\title{
Reuse of Industrial and Agricultural Waste in the Fabrication of Geopolymeric Binders: Mechanical and Microstructural Behavior
}

\author{
Jordi Payá (D), Lourdes Soriano (D), Alba Font, Maria Victoria Borrachero Rosado *, Javier Alejandro Nande $\mathbb{D}$ \\ and Jose María Monzo Balbuena (D)
}

check for

updates

Citation: Payá, J.; Soriano, L.; Font, A.; Borrachero Rosado, M.V.; Nande, J.A.; Monzo Balbuena, J.M. Reuse of Industrial and Agricultural Waste in the Fabrication of Geopolymeric Binders: Mechanical and Microstructural Behavior. Materials 2021, 14, 2089. https://doi.org/ $10.3390 /$ ma14092089

Academic Editor: Francisco Agrela

Received: 31 March 2021

Accepted: 19 April 2021

Published: 21 April 2021

Publisher's Note: MDPI stays neutral with regard to jurisdictional claims in published maps and institutional affiliations.

Copyright: (c) 2021 by the authors. Licensee MDPI, Basel, Switzerland. This article is an open access article distributed under the terms and conditions of the Creative Commons Attribution (CC BY) license (https:/ / creativecommons.org/licenses/by/ $4.0 /)$.
ICITECH-GIQUIMA Grupo de Investigación en Química de los Materiales de Construcción, Instituto de Ciencia y Tecnología del Hormigón, Universitat Politècnica de València, 46022 València, Spain; jjpaya@cst.upv.es (J.P.); lousomar@upvnet.upv.es (L.S.); fontpeal@gmail.com (A.F.); javier.nande90@gmail.com (J.A.N.); jmmonzo@cst.upv.es (J.M.M.B.)

* Correspondence: vborrachero@cst.upv.es

\begin{abstract}
Resource recovery from waste is one of the most important ways to implement the socalled circular economy, and the use of alkali activated materials can become an alternative for traditional PC-based materials. These types of materials are based on waste resources involving a lower carbon footprint and present similar or high properties and good durability compared to that Portland cement (PC). This research work proposes using new waste generated in different types of industries. Four waste types were employed: fluid catalytic cracking residue (FCC) from the petrochemical industry; ceramic sanitary ware (CSW) from the construction industry; rice husk ash (RHA); diatomaceous waste from beer filtration (DB) (food industry). FCC and CSW were employed as precursor materials, and mixtures of both showed good properties of the obtained alkali activated materials generated with commercial products as activators ( $\mathrm{NaOH} /$ waterglass). RHA and DB were herein used as an alternative silica source to prepare the alkaline activating solution. Mechanical behavior was studied by the compressive strength development of mortars. The corresponding pastes were characterized by X-ray diffraction, thermogravimetric analysis, and microscopy studies. The results were satisfactory, and demonstrated that employing these alternative activators from waste produces alkali activated materials with good mechanical properties, which were sometimes similar or even better than those obtained with commercial reagents.
\end{abstract}

Keywords: fluid catalytic cracking residue; ceramic sanitary ware; rice husk ash; diatomaceous earth; waste; alkali activated materials; resource recovery

\section{Introduction}

Sustainable Development Goals (SDGs) call to work towards prosperity while protecting the planet. The United Nations proposed 17 goals to transform the world. Goal 13 indicates the need to take urgent action to combat climate change and its impacts [1].

Global carbon dioxide $\left(\mathrm{CO}_{2}\right)$ emissions have grown around 50\% since 1990, and emissions have grown even more quickly between 2000 and 2010 than in the three previous decades. $\mathrm{CO}_{2}$ is one of the greenhouse gases responsible for the climate change [2].

The cement industry is responsible for about $8 \%$ of global $\mathrm{CO}_{2}$ emissions, of which $5 \%$ are caused by the carbonate decomposition process [3]. For this reason, all alternatives that can reduce cement use are welcome to reduce gas emission levels. Shi et al. reviewed the recent progress in low-carbon binder [4] by writing about the principal groups of low-carbon binders: alkali-activated cements and geopolymers, carbonate binders, beliteye'elimite-ferrite binders. With alkali-activated cements and geopolymers, precursor materials in most cases are by-products or waste from other industries [5-8]. It is true, as Shi et al. [4] stated, that a critical point for employing this type of materials is the availability 
of these materials in specific locations. Additionally, the reactivity and the nature of the reaction products in alkali activated materials depends on the chemical composition of the precursor and activator, and the reaction extent [9].

In the last decade, researchers have investigated the use of waste to totally or partially replace commercial reagents in manufacturing geopolymers or alkali-activated cements [10-13]. The use of RHA as a silica source has been explored in different publications with diverse treatments to obtain the activator, and combining them with various precursors [1-18]. For example, Geraldo et al. [18] carried out a treatment of RHA with $\mathrm{NaOH}$ lasting $30 \mathrm{~min}$ at $90^{\circ} \mathrm{C}$ with a magnetic stirrer. Kamseu et al. [16] introduced RHA into $\mathrm{NaOH}$ solution, and the mixture was ball-milled in a porcelain jar for $40 \mathrm{~min}$.

Mellado et al. [19] studied the reducing $\mathrm{CO}_{2}$ emissions in mortars with FCC and RHA as silica sources. They concluded that the mortar with RHA presented a $50 \%$ reduction compared to the mortar prepared with $\mathrm{Na}_{2} \mathrm{SiO}_{3}$. Pasuello et al. [20] studied the life cycle impact assessment (LCA) with different categories. They concluded that the mortar with RHA could reduce impacts in six of the nine parameters assessed, and would lead to a reduction of more than $70 \%$ in the global warming potential (GWP) compared to the Portland cement (PC) mortar.

The use of diatomaceous earth (DE) as an activator is less known than RHA. The first reference was published by Mejía et al. [21], who compared the use of RHA and calcined spent DE from the brewing industry, using fly ash (FA) and metakaolin (MK) as precursors. They described the silica source dissolution process by $\mathrm{NaOH}$ : the mixture of both components was suspended in water and stirred for $24 \mathrm{~h}$ at room temperature. Bagci et al. [22] used natural DE and calcined the material at $400^{\circ} \mathrm{C}$, which was mixed with MK as a precursor. To dissolve the silica from $\mathrm{DE}$, the authors mixed $\mathrm{KOH}$, deionized water, and DE in a closed container, and the mixture was stirred overnight. Finally, Font et al. [23] employed dried diatomaceous earth that derived from the beer filtration process (DB) and used FCC as precursor. They dissolved the silica of the $\mathrm{DB}$ with $\mathrm{NaOH}$ in a thermal bottle for $24 \mathrm{~h}$.

A review is presented of the current production data of all the waste types herein employed. Around 840,000 metric tons of FCC are produced worldwide per year [24]. The production of FCC in 2019 came to 423 tons (data provided by the BP refinery located in Grao de Castellón, Spain). In the present research work, the FCC from this refinery was used because it is the closest refinery to the university facilities. Ten refineries operate in Spain. It has been demonstrated that the diverse origins of catalysts do not affect their reactivity as pozzolan in cement matrices [25]. A study should be conducted to verify that there is no difference in alkali activated matrices either.

The other material employed in large quantities to produce alkali activated matrices is CSW. The products catalogued as CSW are diverse, and include bidets, cisterns, sinks, etc. The weight of such products is between $7.6 \mathrm{~kg}$ and $39.5 \mathrm{~kg}$ per piece [26]. Using the data published by Cuviella et al. [27] on the worldwide CSW production in 2014 (349.3 millions of pieces), and considering an average weight of $20 \mathrm{~kg}$ per piece, the CSW production in 2014 was around 7 million tons, and production in Europe was around 1.18 million tons. If we take into account that rejected pieces are around 5-7\% [28], rejected CSW would be around 70,800 tons only in Europe. To this quantity we should add the pieces collected from demolition practices, for which no data are available.

Moaeyedi et al. [29] published a paper with RHA applications based on the data of the Food and Agricultural Organization of the United Nations (FAO). They published that the worldwide rice production in 2016 was 533 million tons. One ton of rice produces 0.2 of husk, and one ton of husk generates $220 \mathrm{~kg}$ of ash. Therefore, the potential amount of RHA produced in 2016 would have been some 23.45 million tons. Aprianti [30] published data about the world's RHA production. The data for 2013 in Europe gave 0.1 million ton. Spain is the second largest rice producer in Europe behind Italy. According to data from the Spanish Ministry of Agriculture, Fisheries and Food [31], the RHA produced in 2015 came to 37,100 tons. 
Finally, DB production was estimated from published data. Dessalew et al. [32] indicated for each liter of beer, around 17.14 grams of brewery spent diatomite sludge is produced, and the moisture of this sludge is $70 \%$ : around 5.14 grams of dry spent diatomite is produced for 1 liter of manufactured beer. This sludge needs to be treated, but is often dumped in landfills. In 2017, 3.6 billion liters of beer were produced in Spain [33]. According to the figures proposed by Dessalew et al. [32], the calculated quantity of spent diatomite produced in Spain would be around 1850 tons of DB.

The authors of the present paper studied the viability of manufacture alkali activated binders using local waste. The starting point for this research was a previous publication, in which a mixture of fluid catalytic cracking residue (FCC) and ceramic sanitary ware (CSW) was used as a precursor and commercial reagents as activators $\left(\mathrm{NaOH}\right.$ and $\left.\mathrm{Na}_{2} \mathrm{SiO}_{3}\right)$ [34]. The influence of the replacement percentage of CSW by FCC, and also of the $\mathrm{SiO}_{2}$ concentration in the activator were herein studied. It was concluded that the addition of FCC improved the mechanical properties of CSW-based binders. The best results were obtained by the mortars with $50 \%$ FCC and using $7.28 \mathrm{~mol}_{\text {of }} \mathrm{SiO}_{2}$ per kg of water. However, the compressive strength value obtained with the mortar with $30 \%$ FCC and using $4.37 \mathrm{~mol}$ of $\mathrm{SiO}_{2}$ per $\mathrm{kg}$ of water was sufficient according to common construction use requirements. The novelty of the present research lies in employing alternative sources of silica to replace the use of waterglass for activating CSW and FCC as precursors. Selected alternative sources of silica are rice husk ash (RHA) and a diatomaceous earth deriving from the beer filtration process $(\mathrm{DB})$.

The objective of the present research was to study the compressive strength and physico-chemical characteristics of the first alkali activated mixtures employing FCC and CSW as precursors and RHA and DB as alternative activators. Two types of curing conditions were tested to compare the reaction evolution at different temperatures. To support the behavior of the obtained materials, an analysis of the corresponding pastes was carried out.

\section{Materials and Methods}

\subsection{Materials}

FCC was supplied by BP Oil España S.A.U (Grao de Castellón, Spain) and CSW by Ideal Standard S.L.U (Valencia, Spain). FCC is the catalyst used after the cracking process, and CSW is material that derives from rejected units. Both materials must undergo a conditioning process to obtain the required fineness to improve their reactivity. FCC was milled in an industrial mill by Omya Clariana S.A (Tarragona, Spain). CSW units were firstly broken manually with a hammer and then placed inside a jab crusher (Restch BB200 model, Germany) to obtain a particle size less than $2 \mathrm{~mm}$. Then the crushed CSW was milled in a jar roller mill for $6 \mathrm{~h}$ (Gabbrielli Roller 1 model, Calenzano, Italy)

Alkaline solutions were prepared by two methods: commercial reagents and an alternative silica source. The dissolution based on commercial reagents employed $\mathrm{NaOH}$ pellets of $98 \%$ purity (Panreac Quimica S.L.U, (Barcelona Spain) and $\mathrm{Na}_{2} \mathrm{SiO}_{3}\left(28 \% \mathrm{SiO}_{2}\right.$, $8 \% \mathrm{Na}_{2} \mathrm{O}, 64 \% \mathrm{H}_{2} \mathrm{O}$ ) supplied by Merck S.L.U. (Barcelona, Spain) The dissolutions based on the alternative silica source were prepared, using a thermal bottle to dissolve RHA or DB with $\mathrm{NaOH}$ and $\mathrm{H}_{2} \mathrm{O}$ for $24 \mathrm{~h}$. RHA was supplied by Dacsa S.A (Tavernes Blanques, Spain) and was milled in an industrial mill for $4 \mathrm{~h}$. DB was supplied by Heineken España (Quart de Poblet, Spain) and was oven-dried at $105^{\circ} \mathrm{C}$ for $24 \mathrm{~h}$ to remove moisture.

The chemical compositions of the waste materials are shown in Table 1. The equipment employed to analyze the composition was a Philips Magic Pro Spectrometer by the Xray fluorescence (XRF) Technique. As we can see in Table 1, RHA and DB had a higher percentage of silica. In both cases, the quantity of this oxide was employed to calculate its dose during the alternative silicate preparation for pastes and mortars. 
Table 1. Chemical composition of FCC, CSW, RHA, and DB (wt\%).

\begin{tabular}{cccccccccc}
\hline & $\mathbf{A l}_{\mathbf{2}} \mathbf{O}_{\mathbf{3}}$ & $\mathbf{S i O}_{\mathbf{2}}$ & $\mathbf{C a O}$ & $\mathbf{F e}_{\mathbf{2}} \mathbf{O}_{\mathbf{3}}$ & $\mathbf{K}_{\mathbf{2}} \mathbf{O}$ & $\mathbf{N a}_{\mathbf{2}} \mathbf{O}$ & $\mathbf{P}_{\mathbf{2}} \mathbf{O}_{\mathbf{5}}$ & Other & LOI $^{*}$ \\
\hline FCC & 49.26 & 47.76 & 0.11 & 0.60 & 0.02 & 0.31 & 0.01 & 1.42 & 0.51 \\
$\mathrm{CSW}$ & 23.60 & 66.00 & 1.20 & 1.30 & 2.80 & 2.40 & 0.50 & 2.00 & 0.20 \\
$\mathrm{RHA}$ & 0.25 & 85.58 & 1.83 & 0.21 & 3.39 & - & 0.67 & 1.08 & 6.99 \\
$\mathrm{DB}$ & 5.67 & 81.70 & 1.28 & 3.71 & 0.86 & 1.30 & 0.36 & 1.78 & 3.34 \\
\hline
\end{tabular}

The mean particle diameter of the particles of FCC, CSW, RHA, and DB was $17.12 \mu \mathrm{m}$, $31.24 \mu \mathrm{m}, 20.30 \mu \mathrm{m}$, and $46.40 \mu \mathrm{m}$, respectively. These values were obtained by a laser dispersion analysis in a Mastersizer 2000 (Malvern Instruments, Malvern, U.K.). In Figure 1a,b the particle size distribution curves of starting materials are shown.

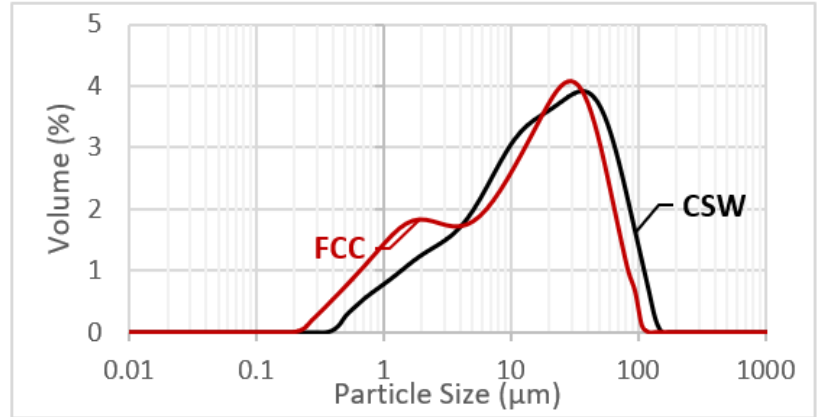

(a)

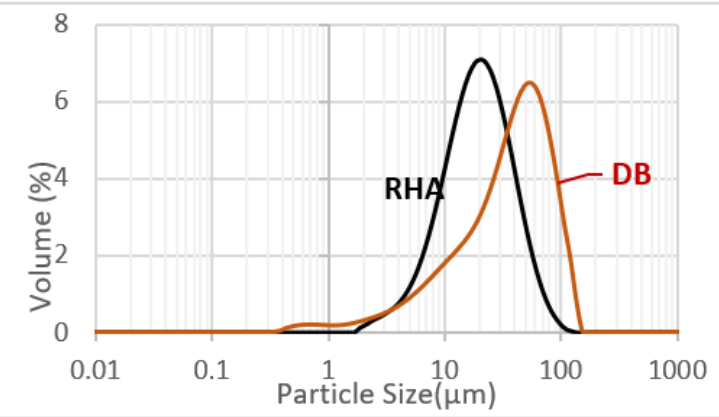

(b)

Figure 1. Particle size distribution curves by laser granulometry technique: (a) FCC and CSW; (b) RHA and DB.

The XRD spectra of the waste materials are represented in Figure 2. The equipment employed was a Brucker AXS D8 Advance (Billerica, Germany). XRD spectra were measured from $10^{\circ}$ to $70^{\circ} 2 \theta$ at $20 \mathrm{~mA}$ and $40 \mathrm{kV}$ with an angle step of $0.02^{\circ}$. The accumulation time in this step was 2 seconds. CSW presented as crystalline phases: quartz $\left(\mathrm{Q}, \mathrm{SiO}_{2}\right.$, PDFcard 331161), mullite (M, $\mathrm{Al}_{6} \mathrm{Si}_{2} \mathrm{O}_{13}$, PDFcard 150776) and anorthite $\left(\mathrm{A}, \mathrm{CaAl}_{2} \mathrm{Si}_{2} \mathrm{O}_{8}\right.$, PDFcard 411486). FCC also presented quartz and mullite, and it contained the presence of albite $\left(\mathrm{B}, \mathrm{NaAlSi}_{3} \mathrm{O}_{8}, \mathrm{PDF}\right.$ card 200554) and faujasite $\left(\mathrm{F}, \mathrm{Na}_{2} \mathrm{Al}_{2} \mathrm{Si}_{4} \mathrm{O}_{12} .8 \mathrm{H}_{2} \mathrm{O}, \mathrm{PDF}\right.$ ard 391380). The main crystalline peaks of RHA and DB were associated with silica, and peaks were quartz and cristobalite $\left(\mathrm{T}, \mathrm{SiO}_{2}, \mathrm{PDF}\right.$ card 391425). The presence of anorthite was observed in DB, and silvine ( $\mathrm{KCl}$, PDFcard 411476) was noted in RHA.
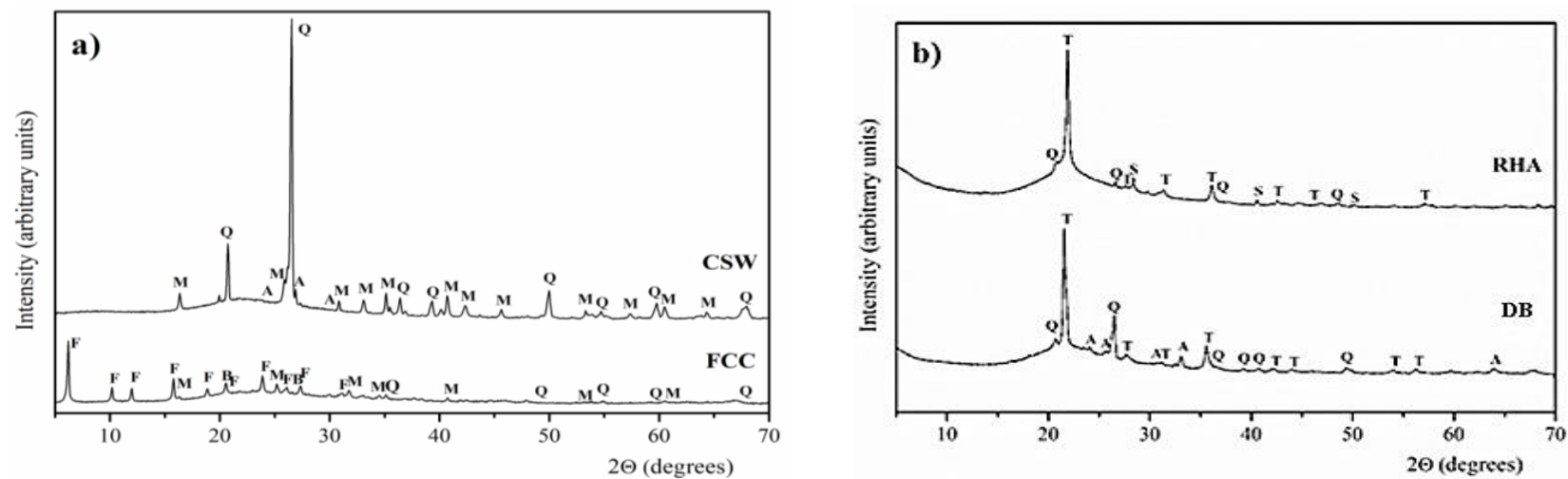

Figure 2. X-ray diffractograms of raw materials: (a) FCC, CSW; (b) RHA, DB (Q: quartz, M: mullite, A: anortite, B: albite, F: faujasite, T: cristobalite, S: silvine). 


\subsection{Experimental Procedure}

As mentioned before in the Introduction, in this research an already published work was taken as a reference [34]. In the activator, the molar $\mathrm{SiO}_{2} / \mathrm{Na}_{2} \mathrm{O}$ ratio was 1.16 and the proportion of $\mathrm{Na}_{2} \mathrm{O}$ was $1.69 \mathrm{~mol}$ per $\mathrm{kg}$ of precursor. The precursor was the sum of CSW and FCC. The water/binder and sand/binder ratios were 0.45 and 3, respectively. The employed siliceous sand had a fineness modulus of 4.1 and a humidity percentage below $0.1 \%$. To enhance CSW reactivity, a calcium source [35] $\left(4 \% \mathrm{Ca}(\mathrm{OH})_{2}\right.$ in relation to the mass of the precursor) was added to the studied mixes. The same dose was employed to prepare pastes, but without sand.

Table 2 summarizes the dose and nomenclature for the analyzed pastes and mortars. Two CSW /FCC proportions were studied: (i) 70\% CSW with 30\% FCC (7-3 system); (ii) 50\% CSW with 50\% FCC (5-5 system). For each mixture of precursors, the alkaline dissolution was prepared with commercial (C) and alternative components: $\mathrm{RHA}+\mathrm{NaOH}(\mathrm{R})$ and $\mathrm{DB}$ $+\mathrm{NaOH}(\mathrm{D})$. The symbol " $\mathrm{m}$ " represents the mortar specimens, while symbol " $\mathrm{p}$ " denotes paste ones.

Table 2. Dose of mortars and pastes.

\begin{tabular}{|c|c|c|c|c|c|c|c|c|c|}
\hline & $\begin{array}{c}\text { CSW } \\
(\mathrm{g})\end{array}$ & $\begin{array}{c}\text { FCC } \\
(\mathrm{g})\end{array}$ & $\begin{array}{c}\mathrm{Na}_{2} \mathrm{SiO}_{3} \\
\text { (g) }\end{array}$ & $\begin{array}{c}\mathrm{NaOH} \\
\text { (g) }\end{array}$ & $\begin{array}{c}\mathrm{H}_{2} \mathrm{O} \\
(\mathrm{g})\end{array}$ & $\begin{array}{c}\text { RHA } \\
\text { (g) }\end{array}$ & $\begin{array}{l}\text { DB } \\
(g)\end{array}$ & $\begin{array}{l}\mathrm{Ca}(\mathrm{OH})_{2} \\
(\mathrm{~g})\end{array}$ & $\begin{array}{c}\text { Sand } \\
\text { (g) }\end{array}$ \\
\hline$m-7-3-C$ & 315.0 & 135.0 & 189.8 & 41.2 & 81.0 & - & - & 18.0 & 1350.0 \\
\hline $\mathrm{m}-7-3-\mathrm{R}$ & 315.0 & 135.0 & _ & 60.8 & 202.5 & 62.1 & & 18.0 & 1350.0 \\
\hline$m-7-3-D$ & 315.0 & 135.0 & - & 60.8 & 202.5 & _ & 65.1 & 18.0 & 1350.0 \\
\hline$m-5-5-C$ & 225.0 & 225.0 & 189.8 & 41.2 & 81.0 & - & - & 18.0 & 1350.0 \\
\hline$m-5-5-R$ & 225.0 & 225.0 & _ & 60.8 & 202.5 & 62.1 & 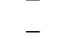 & 18.0 & 1350.0 \\
\hline$m-5-5-D$ & 225.0 & 225.0 & _ & 60.8 & 202.5 & _ & 65.1 & 18.0 & 1350.0 \\
\hline p-7-3-C & 14.0 & 6.0 & 8.4 & 1.8 & 3.6 & - & - & 0.8 & - \\
\hline p-7-3-R & 14.0 & 6.0 & _ & 2.7 & 9.0 & 2.8 & - & 0.8 & - \\
\hline p-7-3-D & 14.0 & 6.0 & - & 2.7 & 9.0 & - & 2.9 & 0.8 & - \\
\hline$p-5-5-C$ & 10.0 & 10.0 & 8.4 & 1.8 & 3.6 & - & - & 0.8 & - \\
\hline$p-5-5-R$ & 10.0 & 10.0 & _ & 2.7 & 9.0 & 2.8 & - & 0.8 & - \\
\hline p-5-5-D & 10.0 & 10.0 & - & 2.7 & 9.0 & - & 2.9 & 0.8 & - \\
\hline
\end{tabular}

The materials were cured under two conditions: in a thermal bath at $65^{\circ} \mathrm{C}$ and $100 \%$ relative humidity for 7 days (mortars were demolded after $6 \mathrm{~h}$ and then cured for up 7 days); at room temperature ( $20{ }^{\circ} \mathrm{C}$ and $95 \%$ relative humidity) for 28 and 90 days.

Compressive strength was measured in specimens $\left(4 \times 4 \times 16 \mathrm{~cm}^{3}\right)$ according to Standard UNE-EN 196-1 [36]. Pastes were analyzed by different techniques (TG, XRD, FESEM). Thermogravimetric analyses were performed in a Mettler Toledo TGA 850 thermobalance (Germany) using a nitrogen atmosphere and a flow gas of $75 \mathrm{~mL} / \mathrm{min}$. The used crucibles were aluminum with pinholed lids. The analysis heat range went from $35^{\circ} \mathrm{C}$ to $600{ }^{\circ} \mathrm{C}$ at a heating rate of $10^{\circ} \mathrm{C} / \mathrm{min}$. The equipment utilized for the XRD analysis is previously described. Pastes were carbon-coated to characterize the reaction products by FESEM using FESEM ULTRA 55 (Zeiss, Jena, Germany).

\section{Results and Discussion}

\subsection{Compressive Strength}

The compressive strengths of the mortars cured under the different assessed conditions are shown in Figure 3. We can see that the mortars with DB as a silica source (7-3-D and 5-5-D) had lower compressive strength than the mortars activated with both commercial reagents and the RHA-based activator. These differences in the mortars activated with RHA and those with DB can be attributed to the fineness of both silica sources: the mean particle size of DB was more than double that of RHA (40.60 vs. $20.30 \mu \mathrm{m})$. The dissolution rate of silica in the $\mathrm{NaOH}$ medium depends on the particle size of the employed silica source, and the amount of silicate in the DB-based activator was probably lower than that of the RHA-based activator. 


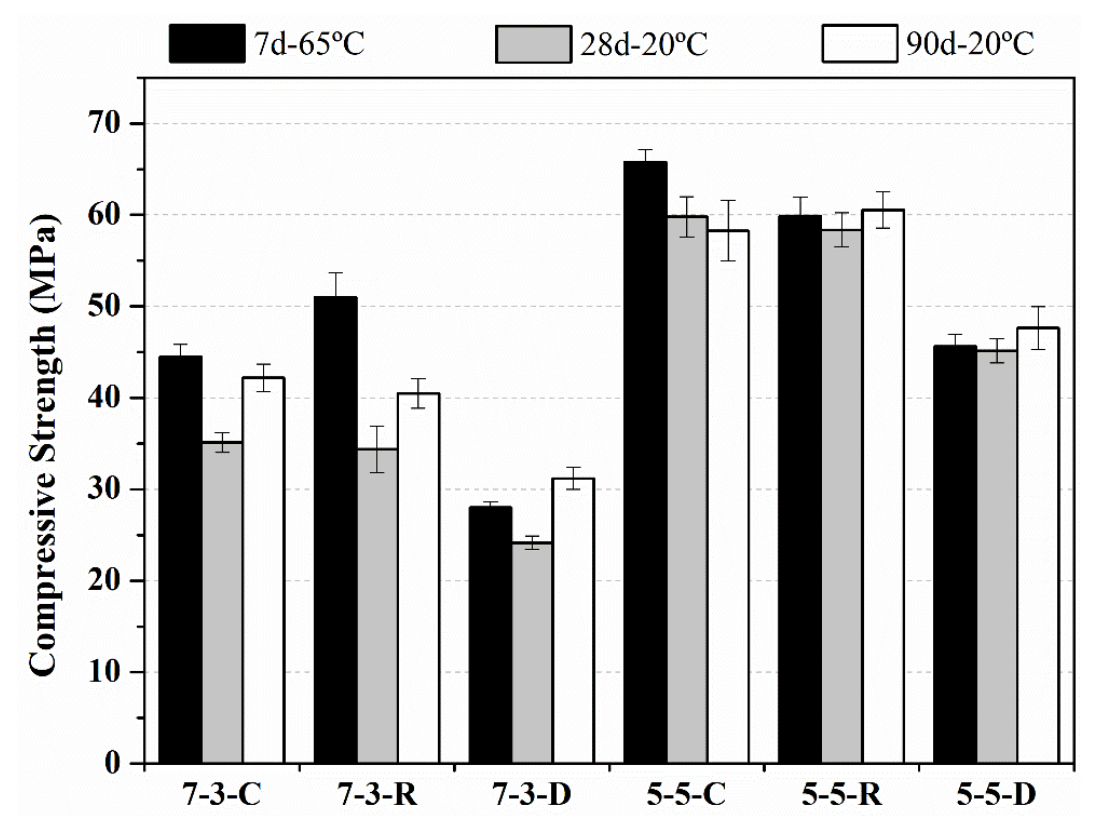

Figure 3. Compressive strength of the mortars cured at $65^{\circ} \mathrm{C}$ for 7 days and cured at $20{ }^{\circ} \mathrm{C}$ for 28 and 90 days.

When DB was employed as a silica source, mortars yielded different behaviors when comparing the precursor proportions (5-5 and 7-3) and curing treatments. For the 5-5-D sample, compressive strength was similar for the different applied curing treatments, with values between $45.2 \mathrm{MPa}$ and $47.6 \mathrm{MPa}$. For the 7-3-D sample, the compressive strength values were lower than those obtained for the 5-5-D sample: this behavior can be attributed to the greater reactivity of FCC as a precursor compared to CSW. Similar values between curing ages for the 7-3-D series were obtained, and ranged between $24.2 \mathrm{MPa}$ and $31.2 \mathrm{MPa}$. This was the worst series of mortars, but the compressive strength values were clearly higher than those of the mortars with only CSW as a precursor and prepared under the same alkaline conditions as the commercial reagents [9]. The compressive strength values of the mortars with only CSW came close to $9 \mathrm{MPa}$ for 7 days curing at $65^{\circ} \mathrm{C}$, but were only 3.7 MPa for the mortars cured for 90 days at $20^{\circ} \mathrm{C}$. The mortars with only FCC as a precursor obtained values of $45.3,61.1$, and $68.5 \mathrm{MPa}$ for 7,28 , and 90 days, respectively. The only mortar with DB that yielded comparable values for the mortar with FCC and commercial reagents was mortar 5-5-D cured for 7 days at $65^{\circ} \mathrm{C}$ [34].

The mixtures of the 5-5 type activated with commercial reagents (5-5-C) and with RHA (5-5-R) obtained the highest compressive strength values, either close to or higher than $60 \mathrm{MPa}$ for all the studied curing conditions. These values are very positive from the practical and environmental point of views because these mixtures contained $50 \% \mathrm{CSW}$, which is a very high reuse CSW percentage. This implies marked CWS valorization, which has hardly been studied to date.

The behavior of the mixtures $7-3$ cured at $65^{\circ} \mathrm{C}$ differ compared to the commercial source and RHA activation: the compressive strength of the 7-3-R mortar was $51 \mathrm{MPa}$ and the 7-3-C mortar yielded 44.5 MPa. For the room temperature curing conditions, the two mortar types yielded a similar compressive strength behavior, with values close to $35 \mathrm{MPa}$ after 28 curing days and $40 \mathrm{MPa}$ after 90 curing days, respectively.

The results obtained in the present research differ from those included in other reports. For example, Mejía et al. [21] obtained similar results for both pastes using DB and RHA, and compressive strength values were clearly lower than those of the paste activated with commercial reagents. They employed a mixture of 70\% FA and 30\% MK. The samples with commercial reagents yielded compressive strength values close to $75 \mathrm{MPa}$ after 360 curing days. The samples with DB and RHA gave 38 and $36 \mathrm{MPa}$, respectively, at the same curing time, but the liquid/solid ratios of mixtures differed from commercial pastes and the 
alternative silicate pastes: 0.3 for the paste with commercial silicate, and 0.45 for the pastes with RHA and DB. These results, compared to those herein obtained, were significantly lower in compressive strength terms. Such behavior can be attributed to differences in the activator's preparation procedure: Mejía et al. [21] only stirred $\mathrm{RHA}+\mathrm{NaOH}$ for $24 \mathrm{~h}$ at room temperature, whereas our silica dissolution process of RHA was more intensive as the heat dissolution of $\mathrm{NaOH}$ increased the temperature of water/RHA or water/DE. We maintained this heat for several hours because the suspension was hermetically stored in a thermal bottle, a process that favors the dissolution of silica from RHA or DB. The work reported by Mejia et al. described how DB was calcined for $3 \mathrm{~h}$ at $400^{\circ} \mathrm{C}$. This treatment can explain the similar behavior of diatomite in relation to RHA. Bagci et al. [22] calcined a natural diatomite. Their compressive strength values in the mixtures with MK of the samples with diatomite were higher than the mixtures activated with silica fume, $71 \mathrm{MPa}$ versus $54 \mathrm{MPa}$, under the combined curing conditions $\left(24 \mathrm{~h}\right.$ at $50{ }^{\circ} \mathrm{C}$ and 6 days at room temperature). In the present study, only DB was dried, but not calcined. Calcination is a procedure that probably increases DB solubility.

\subsection{Thermogravimetric Analysis}

Thermogravimetric analyses were performed for all the pastes under two different curing treatments: 7 days at $65{ }^{\circ} \mathrm{C}$ and 28 days at room temperature. The derivative thermogravimetric curves (DTG) are depicted in Figure 4. For all the analyzed pastes, the DTG curves presented a peak, which appeared at different temperatures depending on the activator and the proportion of precursors used in the formulation. After 7 days at $65^{\circ} \mathrm{C}$, when commercial reagents were employed as an activator $(\mathrm{C})$, the peak centered at $125{ }^{\circ} \mathrm{C}$ for paste $7-3$ and at $152{ }^{\circ} \mathrm{C}$ for paste 5-5. Within the interval of temperatures at which the peak appeared, different gels (N-A-S-H and N-(C)-A-S-H) lost their combined water [37-39].

a)

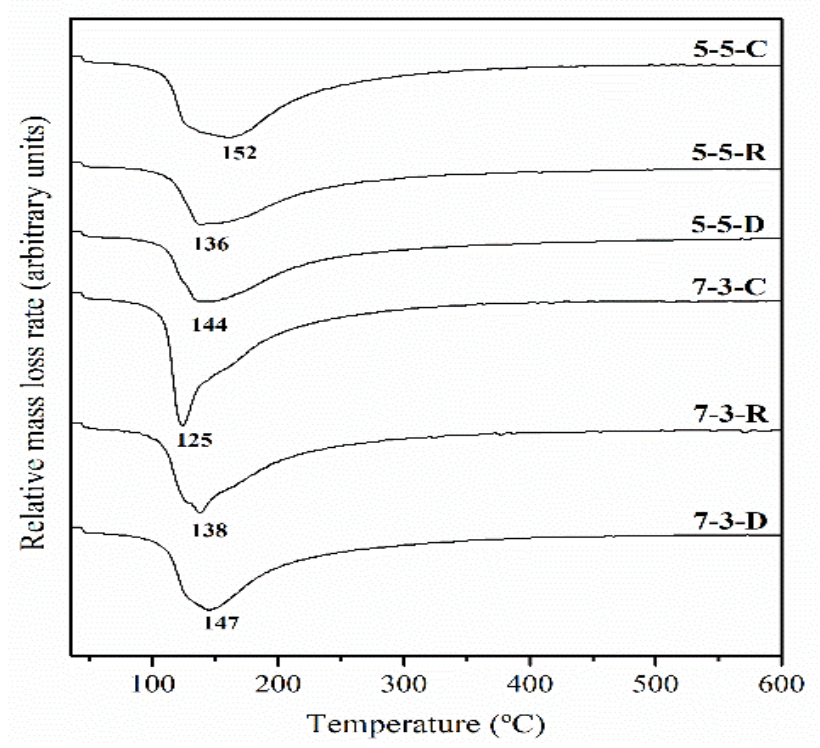

b)

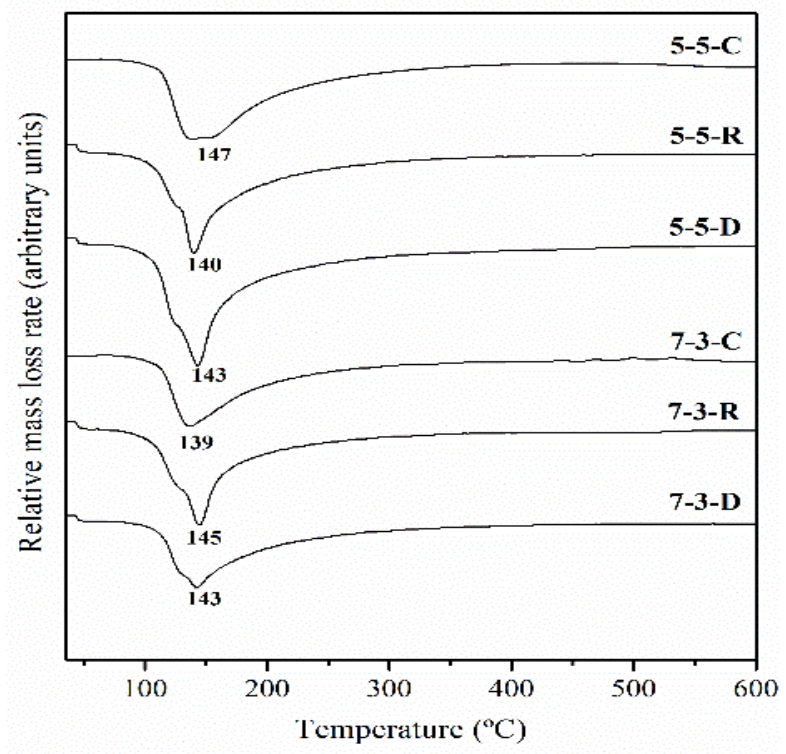

Figure 4. DTG curves: (a) cured for 7 days at $65^{\circ} \mathrm{C}$; (b) cured for 28 days at $20^{\circ} \mathrm{C}$.

Table 3 summarizes the total mass lost between $35^{\circ} \mathrm{C}$ and $600{ }^{\circ} \mathrm{C}$ for the studied pastes. Generally, the highest mass loss was for the paste with the commercial activator. This phenomenon is typical when an alternative activator is employed; e.g., Moraes et. al. [40] compared sugar cane straw ash and commercial sodium silicate. They observed that the paste with the alternative activator had the lower mass loss, but concluded that the formed products were similar. In general, the mass loss at 28 days $/ 20^{\circ} \mathrm{C}$ was lower than 
that at 7 days $/ 65^{\circ} \mathrm{C}$, which might be due to the different reaction kinetics for the two selected temperatures.

Table 3. Thermogravimetric mass loss (as \%) of pastes, between $35^{\circ} \mathrm{C}$ and $600{ }^{\circ} \mathrm{C}$.

\begin{tabular}{ccc}
\hline Paste & $\mathbf{7 ~ d , ~} \mathbf{6 5}{ }^{\circ} \mathbf{C}$ & $\mathbf{2 8 ~ d , ~} \mathbf{2 0}{ }^{\circ} \mathbf{C}$ \\
\hline $7-3-C$ & 11.95 & 8.77 \\
$7-3-R$ & 9.61 & 8.03 \\
$7-3-D$ & 9.72 & 7.44 \\
$5-5-C$ & 11.24 & 10.23 \\
$5-5-R$ & 8.55 & 9.00 \\
$5-5-D$ & 9.83 & 10.77 \\
\hline
\end{tabular}

\subsection{XRD Analysis}

Figure 5 represents the XRD diffractograms of the pastes cured for 28 days. The crystalline compounds presented in the precursors were detected in all the pastes (Q: quartz, A: albite, M: mullite). In the pastes activated with DB and RHA, the presence of cristobalite (T) was also noted, a mineral present at a low proportion in the silica source. These crystalline phases $(\mathrm{Q}, \mathrm{A}, \mathrm{M}, \mathrm{T})$ were nearly inert to geopolymerisation reactions and remained after the curing process.

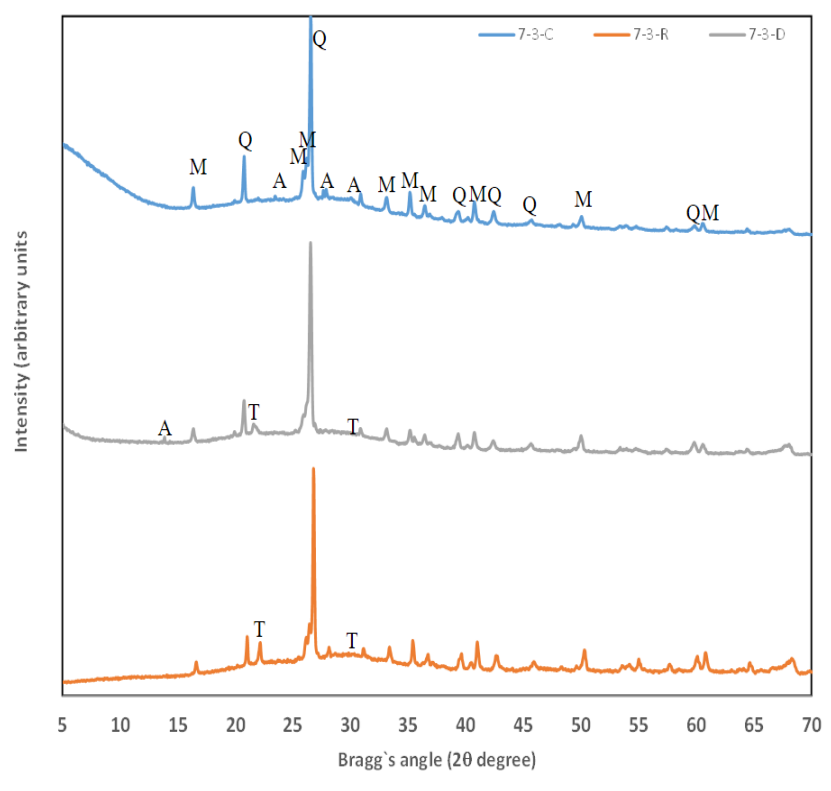

(a)

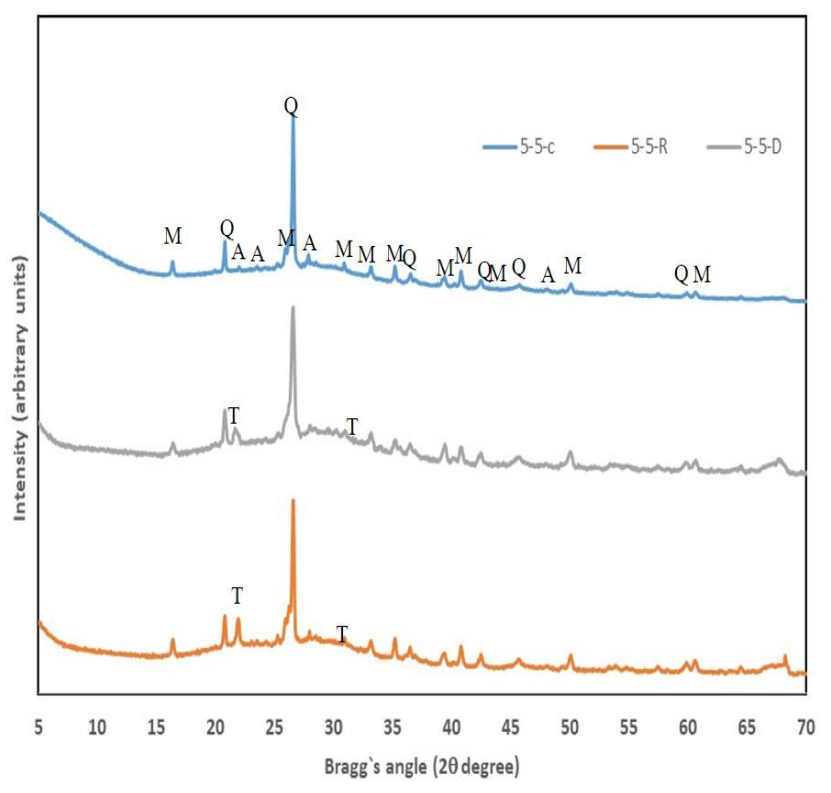

(b)

Figure 5. XRD diffractograms of the pastes cured for 28 days at $20^{\circ} \mathrm{C}$ : (a) 7-3 type; (b) 5-5 type.

It should be noted that the peaks related to the presence of faujasite, a zeolitic phase which is the main crystalline compound present in FCC (Figure 1a), were not detected in paste types 7-3 or 5-5. This fact has been previously reported [41,42] and described how zeolite was dissolved with the activating solution to provide $\mathrm{Al}$ and $\mathrm{Si}$ for the geopolymerisation reaction and the formation of cementitious gel. It is noteworthy that in all the diffractograms, a marked deviation from the baseline took place between $15-40^{\circ} 2 \theta$. This can be attributed to the presence of the N-A-S-H and N-(C)-A-S-H gels formed during the geopolymerisation process [41,43]. Raw materials (CSW, FFC, RHA, DB) presented a deviation (hump or diffuse halo peak) at the baseline (see Figure 1) within the $15-30^{\circ}$ range, and the maximum of the hump fell within the $21-24^{\circ}$ range. After geopolymerisation, the hump shifted to higher $2 \theta$ values, within the $17-40^{\circ}$ range, which meant that cementing gels formed from the dissolution of amorphous phases in raw materials [44]. After the 
reaction, the maximum of the hump in pastes also shifted to higher $2 \theta$ values $\left(26-30^{\circ}\right)$, which indicates the partial dissolution of amorphous phases in raw materials and the yielding of new amorphous phases. The added portlandite was not detected for all the pastes, which suggests that calcium was incorporated into reaction products. Reig et al. verified this fact by following a similar process with porcelain stoneware tiles and CSW activations $[45,46]$.

\subsection{FESEM Analysis}

In Figure 6, FESEM micrographs are shown for pastes 5-5 cured for 7 days at $65^{\circ} \mathrm{C}$ and 28 days at $25^{\circ} \mathrm{C}$, prepared using commercial sodium silicate (Figure 6a,b) as and $\mathrm{NaOH}$ activator, plus RHA (Figure 6c,d) and $\mathrm{NaOH}$ plus DB (Figure 6e,f). In all cases, a dense compact microstructure is observed, even though the pastes cured for 28 days were more compact than those cured at $65^{\circ} \mathrm{C}$. This would agree with the high strength found for the corresponding mortars.

In the pastes with commercial silicate, unreacted CSW particles were observed and particles were partially covered by the reaction products (Figure 6a,b). The principal products were N-A-S-H and N/C)A-S-H gels. These gel products have been previously detected [9]. Similarly in the mixtures with MK, which is a similar precursor to FCC, and using RHA as the silica source, the presence of this gel type has been reported by Kamseu et al. [16]. This gel was formed by the agglomeration of nanoparticles (detailed in Figure 7).

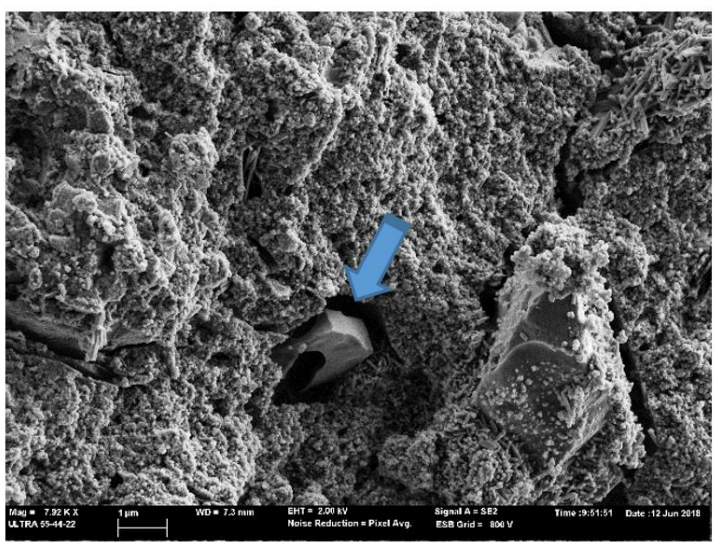

(a)

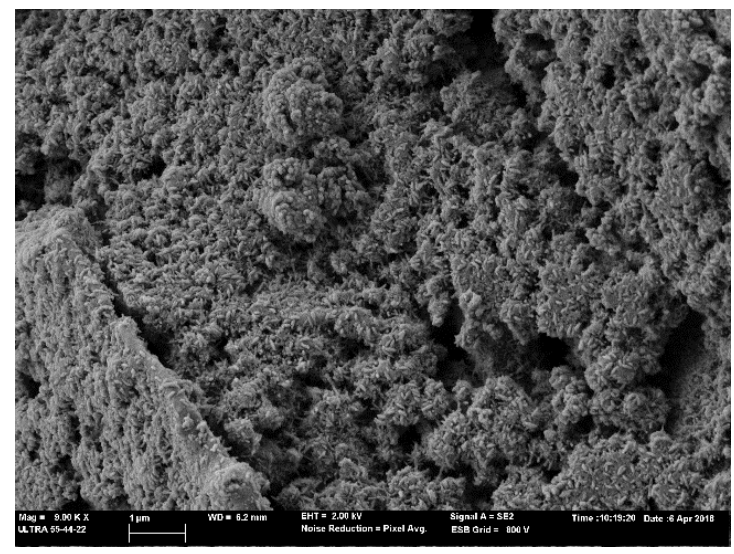

(c)

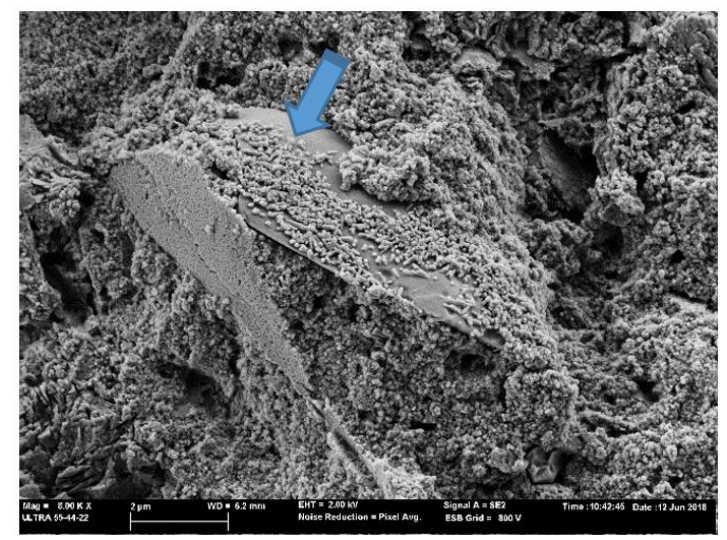

(b)

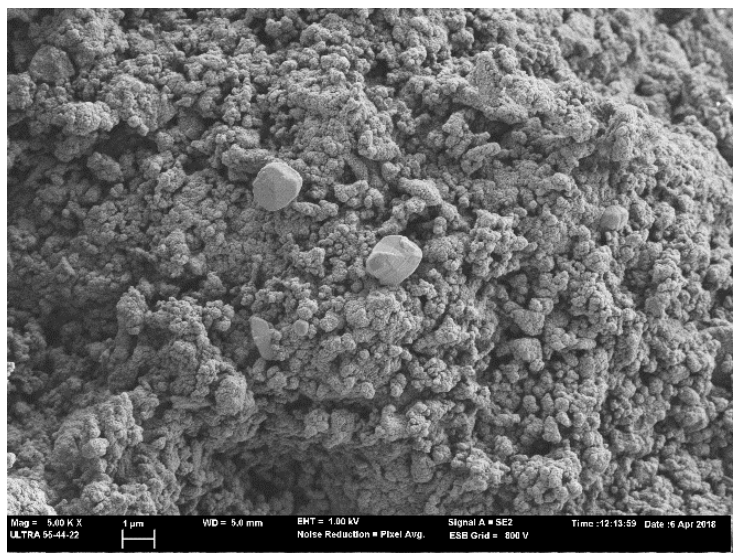

(d)

Figure 6. Cont. 


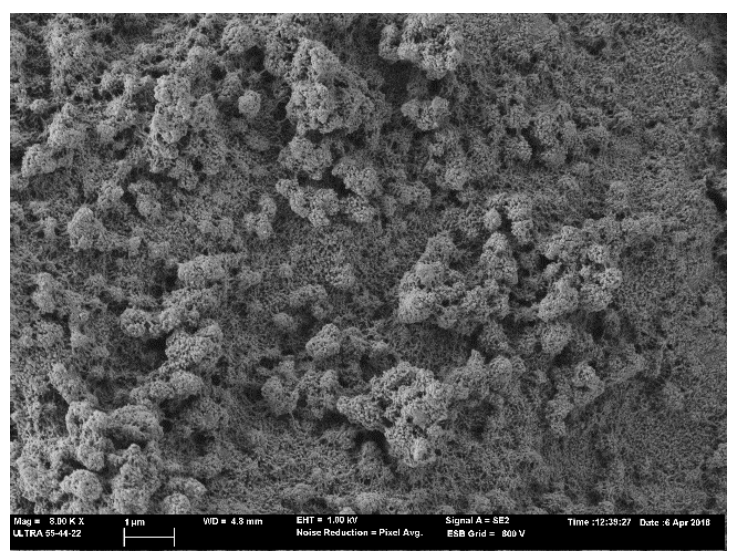

(e)

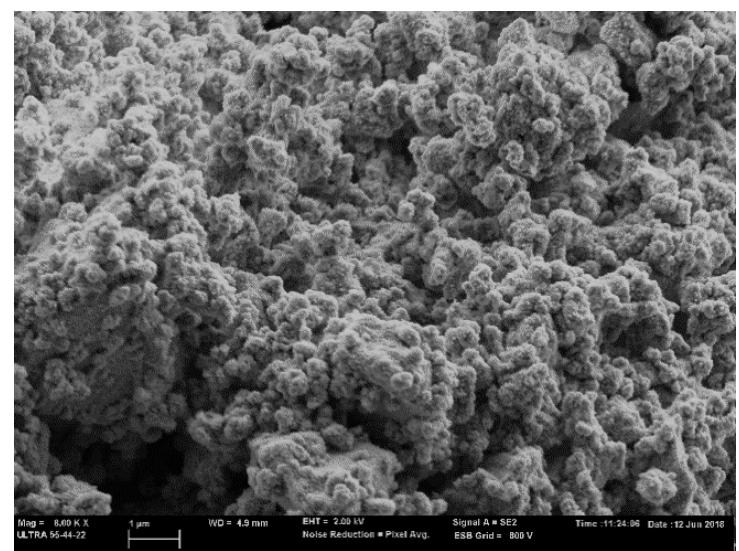

(f)

Figure 6. FESEM micrographs for the 5-5 type pastes cured at $65^{\circ} \mathrm{C} / 7$ days and $20{ }^{\circ} \mathrm{C} / 28$ days. Arrows indicate unreacted CSW particles. (a) $5-5 \mathrm{C}$ paste cured $7 \mathrm{~d} 65^{\circ} \mathrm{C}$; (b) $5-5-\mathrm{C}$ paste cured $28 \mathrm{~d} 20{ }^{\circ} \mathrm{C}$, (c) $5-5-\mathrm{R}$ paste cured $7 \mathrm{~d} 65^{\circ} \mathrm{C}$, (d) $5-5-\mathrm{R}$ paste cured $28 \mathrm{~d} 20^{\circ} \mathrm{C}$, (e) $5-5-\mathrm{D}$ paste cured $7 \mathrm{~d} 65^{\circ} \mathrm{C}$, (f) $5-5-\mathrm{D}$ paste cured $28 \mathrm{~d} 20^{\circ} \mathrm{C}$.

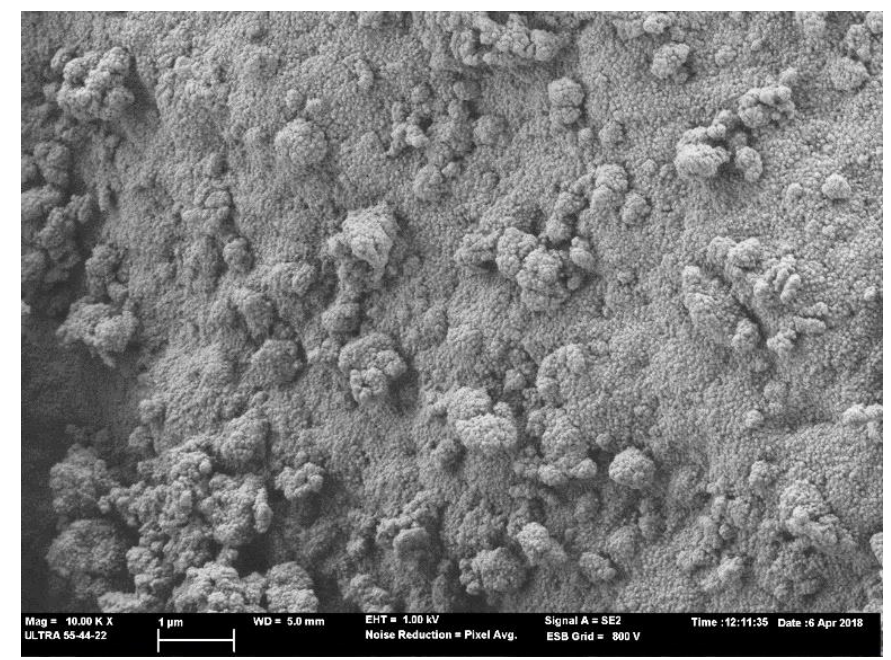

Figure 7. FESEM micrograph of the 5-5-R paste cured at $20{ }^{\circ} \mathrm{C}$ for 28 days: detailed view of the cementing gel.

\section{Conclusions}

The main conclusions of this research work are summarized below:

- The mortars activated with RHA were comparable to the behavior of the mixtures activated with commercial reagents. The best option for reaching high compressive strength was to use the precursor with the 5-5 FCC/CSW ratio.

- Activation with DB obtained lower compressive strength values than the other matrices, but this strength sufficed for applications, which require strength below $50 \mathrm{MPa}$ for the mixtures with the 5-5 ratio of precursors, and around $30 \mathrm{MPa}$ with the 7-3 ratio.

- The main reaction product was a mixed gel, N-A-S-H and N-(C)-A-S-H, as corroborated by the TG, XRD, and FESEM analyses.

We generally conclude that the CSW/FCC binary mixtures can be an alternative as a precursor for preparing alkali-activated materials, and they obtained good mechanical strength results.

The possibility of using residual materials rich in silica, such as RHA and DB as part of the activator in alkali activated mixtures, was also demonstrated with similar mechanical strength and microstructure results to those obtained with commercial sodium silicate. This proposal contributes to materials sustainability. 
Author Contributions: J.A.N. has done much of the experimental of this work. L.S. and A.F. have contributed to the thermogravimetric, the mechanical and the FESEM tests. Furthermore, they have involved in the writing: the manuscript preparation, review and editing. J.P. and J.M.M.B. have supported to the research planning, and the manuscript writing and review. M.V.B.R. has been the director investigation. She has identified the DRX patterns and written the original draft, review and editing the manuscript. All authors have read and agreed to the published version of the manuscript.

Funding: This research was funded by the Spanish Government and FEDER funds (MINECO/FEDERProject RTI2018-09612-B-C21).

Institutional Review Board Statement: Not applicable.

Informed Consent Statement: Not applicable.

Data Availability Statement: The data presented in this study are available on request from the corresponding author.

Acknowledgments: This research work forms part of a project supported by MINECO and FEDER funds (ECOSOST RTI2018-097612-B-C21). The authors are grateful to Dacsa Group S.A., BP Oil España S.A.U., Ideal Standard S.L.U. and Heineken España and also to the Electron Microscopy Service of the Universitat Politècnica de València.

Conflicts of Interest: The authors declare no conflict of interest.

\section{Acronyms}

$\begin{array}{ll}\text { FCC } & \text { Fluid catalytic cracking residue } \\ \text { CSW } & \text { Ceramic sanitary ware } \\ \text { RHA } & \text { Rice husk ash } \\ \text { DB } & \text { Diatomaceous waste from beer filtration } \\ \text { SDG } & \text { Sustainable Development Goals } \\ \text { N-A-S-H } & \text { Hydrated sodium aluminosilicate gel } \\ \text { FESEM } & \text { Field emission scanning electron microscopy } \\ \text { N(C)ASH } & \text { Hydrated sodium(calcium)aluminosilicate gel } \\ \text { PC } & \text { Portland cement } \\ \text { DE } & \text { Diatomaceaous earth (bibliography) } \\ \text { FA } & \text { Fly ash } \\ \text { MK } & \text { Metakaolin } \\ \text { XRF } & \text { X-Ray fluorescence } \\ \text { XRD } & \text { X-Ray Diffraction } \\ \text { DTG } & \text { Derivative thermogravimetric curve }\end{array}$

\section{References}

1. Available online: https://www.un.org/sustainabledevelopment/es/ (accessed on 18 April 2021).

2. Available online: https://www.un.org/sustainabledevelopment/climate-change/ (accessed on 18 April 2021).

3. Andrew, R.M. Global $\mathrm{CO}_{2}$ emissions from cement production, 1928-2018. Earth Syst. Sci. Data 2019, 11, 1675-1710. [CrossRef]

4. Shi, C.; Qu, B.; Provis, J.L. Recent progress in low-carbon binders. Cem. Concr. Res. 2019, 122, 227-250. [CrossRef]

5. Robayo, R.A.; Mulford, A.; Munera, J.; Mejía de Gutiérrez, R. Alternative cements based on alkali-activated red clay brick waste. Constr. Build. Mater. 2019, 128, 163-169. [CrossRef]

6. Belmokhtar, N.; Ammari, M.; Brigui, J.; Ben, L. Comparison of the microstructure and the compressive strength of two geopolymers derived from metakaolin and an industrial sludge. Const. Build. Mater. 2017, 146, 621-629. [CrossRef]

7. Thakur, A.K.; Pappu, A.; Thakur, V.K. Synthesis and characterization of new class of geopolymer hybrid composite materials from industrial wastes. J. Clean. Prod. 2019, 230, 11-20. [CrossRef]

8. $\mathrm{Hu}, \mathrm{W}$; $\mathrm{Nie}, \mathrm{Q} . K . ; H u a n g$, B.S.; Shu, X.; He, Q. Mechanical and microstructural characterization of geopolymers derived from red mud and fly ashes. J. Clean. Prod. 2018, 186, 799-806. [CrossRef]

9. Xiao, R.; Jiang, X.; Zhang, M.; Polaczyk, P.; Huang, B. Analytical investigation of phase assemblages of alkali-activated materials in $\mathrm{CaO}-\mathrm{SiO}_{2}-\mathrm{Al}_{2} \mathrm{O}_{3}$ systems: The management of reaction products and designing of precursors. Mat. Des. 2020, $194,108975$. [CrossRef]

10. Fernández-Jiménez, A.; Cristelo, N.; Miranda, T.; Palomo, A. Sustainable alkali activated materials: Precursor and activator derived from industrial wastes. J. Clean. Prod. 2017, 162, 1200-1209. [CrossRef] 
11. Bilginer, A.; Canbek, O.; Erdoğan, S.T. Activation of blast furnace slag with soda production waste. J. Mater. Civ. Eng. 2020, 32, 04019316. [CrossRef]

12. El-Naggar, M.R.; El-Dessouky, M.I. Re-use of wastes glass in improving properties of metakaolin-based geopolymers:mechanical and microstructure examination. Constr. Build. Mater. 2017, 132, 543-555. [CrossRef]

13. Jamieson, E.; Kealley, C.S.; van Riessen, A.; Hart., R.D. Optimising ambient setting Bayer derived fly ash geopolymers. Materials 2016, 9, 392. [CrossRef]

14. Bouzón, N.; Payá, J.; Borrachero, M.V.; Soriano, L.; Tashima, M.M.; Monzó, J. Refluxed rice husk ash/NaOH suspension for preparing alkali activated binders. Mater. Lett. 2014, 115, 72-74. [CrossRef]

15. Mejía, J.M.; Mejía de Gutiérrez, R.; Puertas, F. Rice husk ash as source of silica in alkali-activated fly ash and granulated blast furnae slag systems. Mater. Constr. 2013, 311, 361-375. [CrossRef]

16. Kamseu, E.; Beluk à Moungam, L.M.; Cannio, M.; Billong, N.; Chaysuwan, D.; Chinje Melo, U.; Leonelli, C. Substitution of sodium silcate with rice husk ash- $\mathrm{NaOH}$ solution in metakaolin based geopolymer cement concerning reduction in global warming. $J$. Clean. Prod. 2017, 142, 3050-3060. [CrossRef]

17. Luukkonen, T.; Abdollahnejab, Z.; Yliniemi, J.; Kinnunen, P.; Illikainen, M. Comparison of alkali-activated and silica sources in one-part alkali-activated blast furnace slag mortar. J. Clean. Prod. 2018, 187, 171-179. [CrossRef]

18. Geraldo, R.H.; Fernandes, L.F.R.; Camarini, G. Water treatment sludge and rice husk ash to sustainable geopolymer production. J. Clean. Prod. 2017, 149, 146-155. [CrossRef]

19. Mellado, A.; Catalán, C.; Bouzón, N.; Borrachero, M.V.; Monzó, J.M.; Payá, J. Carbon footprint of geopolymeric mortar: Study of the contribution of the alkaline activating solution and assessment of an alternative route. RSC. Adv. 2014, 4, 23846-23853. [CrossRef]

20. Passuello, A.; Rodríguez, E.D.; Hirt, E.; Longhi, M.; Bernal, S.A.; Provis, J.L.; Kirchheim, A.P. Evaluation of the potential improvement in the environmental footprint of geopolymer using waste-derived activators. J. Clean. Prod. 2017, 166, 680-689. [CrossRef]

21. Mejía, J.M.; Mejía de Gutiérrez, R.; Montes, C. Rice husk ash and diatomaceus earth as a source of silica to fabricate a geopolymeric binary binder. J. Clean. Prod. 2016, 118, 133-139. [CrossRef]

22. Bagci, C.; Kutyla, G.P.; Kriven, W.M. Fully reacted high strength geopolymer made with diatomite as a fumed silica alternative. Ceram. Int. 2017, 43, 14784-14790. [CrossRef]

23. Font, A.; Soriano, L.; Reig, L.; Tashima, M.M.; Borrachero, M.V.; Monzó, J.; Payá, J. Use of residual diatomaceus earth as a silica source in geopolymer production. Mater. Lett. 2018, 223, 10-13. [CrossRef]

24. Vogt, E.; Weckhuysen, B.M. Fluid catalytic cracking: Recent developments on the grand old lady of zeolite catalysis. Chem. Soc. Rev. 2015, 44, 7342-7370. [CrossRef] [PubMed]

25. Payá, J.; Borrachero, M.V.; Monzó, J.; Soriano, L. Studies on the behaviour of different spent fluidized-be catalytic cracking catalysts on Portland cement. Mater. Construcción 2009, 59, 37-52. [CrossRef]

26. Lv, J.; Gu, F.; Zhang, W.; Guo, J. Life cycle assessment and life cycle costing of sanitary ware manufacturing a case study in China. J. Clean. Prod. 2019, 238, 117938. [CrossRef]

27. Cuviella, C.; Colmenar, A.; Borge, D.; López, A. Management tool to optimize energy and water consumption in the sanitary-ware industry. J. Clean. Prod. 2018, 197, 280-296. [CrossRef]

28. Medina, C.; Frías, M.; Sánchez de Rojas, M.I. Microstructure and properties of recycled concretes using ceramic sanitary ware industry waste as coarse aggregate. Constr. Build. Mater. 2012, 48, 112-118. [CrossRef]

29. Moaeydi, H.; Aghel, B.; Abdullahi, M.M.; Nguyen, H.; Rashid, A.A.S. Application of rice husk ash as green and sustainable biomass. J. Clean. Prod. 2019, 237, 117851. [CrossRef]

30. Aprianti, E. A huge number of artificial waste material can be supplementary cementitious material (SCM) for concrete productiona review part II. J. Clean. Prod. 2017, 142, 4178-4194. [CrossRef]

31. Available online: https://www.mapa.gob.es/es/agricultura/temas/producciones-agricolas/cultivos-herbaceos/arroz/default. aspx (accessed on 18 April 2021).

32. Dessalew, G.; Beyene, A.; Nebiyu, A.; Ruelle, M.L. Use of industrial diatomite wastes from beer production to improve soil fertility and cereal yields. J. Clean. Prod. 2017, 157, 22-29. [CrossRef]

33. Available online: https:/ /ec.europa.eu/eurostat/en/web/products-eurostat-news/-/EDN-20180803-1 (accessed on 18 April 2021).

34. Cosa, J.; Soriano, L.; Borrachero, M.V.; Reig, L.; Payá, J.; Monzó, J.M. Influence of addition of fluid catalytic cracking residue (FCC) and the $\mathrm{SiO}_{2}$ concentration in alkali-activated ceramic sanitary ware (CSW) binders. Minerals 2018, 8, 123. [CrossRef]

35. Reig, L.; Borrachero, M.V.; Monzó, J.M.; Savastano, H.; Tashima, M.M.; Payá, J. Use of ceramic sanitaryware as an alternative for the development of new sustainable binder. Key Eng. Mater. 2015, 668, 172-180. [CrossRef]

36. UNE-EN 196-1. Methods of Testing Cement-Part 1: Determination of Strength; AENOR: Madrid, Spain, 2005.

37. Ismail, I.; Bernal, S.A.; Provis, J.L.; San Nicolas, R.; Hamdan, S.; Van Deventer, J.S.J. Modification of phase evolution in alkaliactivated blast furnace slag by the incorporation of fly ash. Cem. Concr. Compos. 2014, 45, 125-135. [CrossRef]

38. Nath, S.K. Kumer, Role of particle fineness on engineering properties and microstructural of fly ash derived geopolymer. Constr. Build. Mater. 2020, 233, 117294. [CrossRef]

39. Rodriguez, E.D.; Bernal, S.A.; Provis, J.l.; Payá, J.; Monzó, J.M.; Borrachero, M.V. Effect of nanosilica-based activators on the performance of an alkali-activated fly ash binder. Cem. Concr. Compos. 2013, 35, 1-11. [CrossRef] 
40. Moraes, J.C.B.; Font, A.; Soriano, L.; Akasali, J.L.; Tashima, M.M.; Monzó, J.; Borrachero, M.V.; Payá, J. New use of sugar cane straw ash in alkali-activated materials: A silica source for the preparation of the alkaline activator. Constr. Build. Mater. 2018, 171, 611-621. [CrossRef]

41. Tashima, M.M.; Akasaki, J.L.; Melges, J.L.P.; Soriano, L.; Monzó, J.; Payá, J.; Borrachero, M.V. Alkali activated materials based on fluid catalytic cracking catalyst residue (FCC): Influence of $\mathrm{SiO}_{2} / \mathrm{Na}_{2} \mathrm{O}$ and $\mathrm{H}_{2} \mathrm{O} / \mathrm{FCC}$ ration on mechanical strength and microstructure. Fuel 2013, 108, 833. [CrossRef]

42. Rodriguez, E.D.; Bernal, S.A.; Provis, J.L.; Gehman, J.D.; Monzó, J.; Payá, J.; Borrachero, M.V. Geopolimers based on spent catalyst residue from a fluid catalytic cracking (FCC) process. Fuel. 2013, 109, 493. [CrossRef]

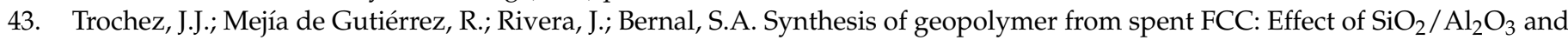
$\mathrm{N}_{\mathrm{a} 2} \mathrm{O} / \mathrm{SiO}_{2}$ molar ratios. Mater. Constr. 2015, 65, 65. [CrossRef]

44. Djobo, J.N.Y.; Tchadjié, L.N.; Tchakoute, H.K.; Kenne, B.B.D.; Elimbi, A.; Njopwouo, D. Synthesis of geopolymer composites from a mixture of volcanic scoria and metakaolin. J. Asian Ceram. Soc. 2014, 2, 387. [CrossRef]

45. Reig, L.; Soriano, L.; Borrachero, M.V.; Monzó, J.; Payá, J. Influence of the activator concentration and calcium hydroxide addition on the properties of alkali-activated porcelain stoneware. Constr. Build. Mater. 2014, 63, 214-222. [CrossRef]

46. Reig, L.; Soriano, L.; Tashima, M.M.; Borrachero, M.V.; Monzó, J.; Payá, J. Influence of calcium additions on the compressive strength and microstructure of alkali-activated ceramic sanitary-ware. J. Am. Ceram. Soc. 2018, 101, 3094-3104. [CrossRef] 